\title{
Sonic hedgehog signalling as a potential endobronchial biomarker in COPD
}

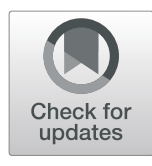

\author{
Julien Ancel ${ }^{1,2}$, Randa Belgacemi ${ }^{1}$, Jeanne-Marie Perotin ${ }^{1,2}$, Zania Diabasana' ${ }^{1}$, Sandra Dury², Maxime Dewolf², \\ Arnaud Bonnomet ${ }^{1,3}$, Nathalie Lalun ${ }^{1}$, Philippe Birembaut ${ }^{1,4}$, Myriam Polette ${ }^{1,4}$, Gaëtan Deslée $e^{1,2}$ and \\ Valérian Dormoy ${ }^{*}$ (D)
}

\begin{abstract}
Background: The hedgehog $(\mathrm{HH})$ pathway has been associated with chronic obstructive pulmonary disease (COPD) in genome-wide association studies and recent studies suggest that $\mathrm{HH}$ signalling could be altered in COPD. We therefore used minimally invasive endobronchial procedures to assess activation of the $\mathrm{HH}$ pathway including the main transcription factor, Gli2, and the ligand, Sonic HH (Shh).

Methods: Thirty non-COPD patients and 28 COPD patients were included. Bronchial brushings, bronchoalveolar lavage fluid (BALF) and bronchial biopsies were obtained from fiberoptic bronchoscopy. Characterization of cell populations and subcellular localization were evaluated by immunostaining. ELISA and RNAseq analysis were performed to identify Shh proteins in BAL and transcripts on lung tissues from non-COPD and COPD patients with validation in an external and independent cohort.

Results: Compared to non-COPD patients, COPD patients exhibited a larger proportion of basal cells in bronchial brushings ( $26 \pm 11 \%$ vs $13 \pm 6 \% ; p<0.0001)$. Airway basal cells of COPD subjects presented less intense nuclear staining for $\mathrm{Gli} 2$ in bronchial brushings and biopsies $(p<0.05)$. Bronchial BALF from COPD patients contained lower Shh concentrations than non-COPD BALF (12.5 vs $40.9 \mathrm{pg} / \mathrm{mL} ; p=0.002) ; \mathrm{SHH}$ transcripts were also reduced in COPD lungs in the validation cohort $(p=0.0001)$.

Conclusion: This study demonstrates the feasibility of assessing HH pathway activation in respiratory samples collected by bronchoscopy and identifies impaired bronchial epithelial HH signalling in COPD.
\end{abstract}

Keywords: Chronic obstructive pulmonary disease, Hedgehog signalling pathway, Airway epithelial cells, Bronchoscopy

\section{Background}

Chronic obstructive pulmonary disease (COPD) is the third leading cause of death worldwide and represents a major public health problem [1]. Tobacco smoke is known to be the main risk factor, leading to epithelial and subepithelial bronchial remodelling [2], including airway basal cell progenitor alterations [3]. These morphological changes result in non-reversible chronic

\footnotetext{
* Correspondence: valerian.dormoy@univ-reims.fr

'University of Reims Champagne-Ardenne, Inserm, P3Cell UMR-S 1250, SFR CAP-SANTE, 45 rue Cognacq-Jay, 51092 Reims, France

Full list of author information is available at the end of the article
}

airflow limitation. The pathophysiology of bronchial epithelial remodelling in COPD is complex, heterogeneous and poorly understood, and its impact on clinical phenotypes remains to be elucidated. Due to the incomplete understanding of the mechanisms leading to epithelial remodelling, no treatment targeting epithelial remodelling in COPD is currently available.

Identification of novel pathways involved in COPD pathophysiology constitutes a challenge in order to personalize patient management [4]. A genome-wide association study identified major susceptibility loci in COPD [5], including enrichment of genes related to signalling

(c) The Author(s). 2020 Open Access This article is licensed under a Creative Commons Attribution 4.0 International License, which permits use, sharing, adaptation, distribution and reproduction in any medium or format, as long as you give appropriate credit to the original author(s) and the source, provide a link to the Creative Commons licence, and indicate if changes were made. The images or other third party material in this article are included in the article's Creative Commons licence, unless indicated otherwise in a credit line to the material. If material is not included in the article's Creative Commons licence and your intended use is not permitted by statutory regulation or exceeds the permitted use, you will need to obtain permission directly from the copyright holder. To view a copy of this licence, visit http://creativecommons.org/licenses/by/4.0/. The Creative Commons Public Domain Dedication waiver (http://creativecommons.org/publicdomain/zero/1.0/) applies to the data made available in this article, unless otherwise stated in a credit line to the data. 
events mediated by the $\mathrm{HH}$ family [6]. Sonic $\mathrm{HH}$ signalling is essential for embryonic lung development, regulating epithelial/mesenchymal cell interactions in airways and parenchyma [7, 8]. HH signalling occurs upon Shh ligand binding and leads to Gli2 nuclear translocation, mainly described as an activator of transcription [9]. HH pathway signalling alterations have been observed in respiratory diseases such as pulmonary fibrosis [10, 11], asthma [12, 13] and lung cancer [14]. We recently demonstrated that the $\mathrm{HH}$ pathway was inextricably linked to airway epithelial cell (AEC) differentiation in adulthood [15]. Interestingly, in vitro interference with $\mathrm{HH}$ induced COPD-like epithelial remodelling, suggesting that Shh signalling may be deficient in COPD. However, assessment of the $\mathrm{HH}$ pathway in clinical practice remains challenging.

Using minimally invasive endobronchial procedures, we assessed the $\mathrm{HH}$ pathway in COPD and non-COPD patients and demonstrated significant impairment of the $\mathrm{HH}$ pathway in COPD.

\section{Methods}

\section{Study population}

COPD and non-COPD control subjects (Fig. 1a) were prospectively recruited from the Department of pulmonary medicine, University Hospital of Reims (France). NonCOPD patients $(n=30)$ with no diagnosis of chronic respiratory disease were recruited from the Department of pulmonary medicine. COPD patients $(n=28)$ were enrolled on the basis of clinical and functional assessments with a forced expiratory volume in $1 \mathrm{~s}\left(\mathrm{FEV}_{1}\right) /$ forced vital capacity $($ FVC $)<0.7$ after bronchodilation. At inclusion, all patients were stable with no acute exacerbation of COPD for 4 weeks. Patients with asthma, cystic fibrosis, tuberculosis, cancer, or other chronic respiratory disease were excluded. Patient characteristics, including demographic data, medical history, treatments, respiratory symptoms and pulmonary function tests (PFT), were collected using a predefined case report form. Subjects who had ceased smoking for more than 6 months were considered to be ex-smokers. The severity of COPD was determined according to the spirometric classification (GOLD 1: $\mathrm{FEV}_{1} \geq 80 \%$ predicted, GOLD 2: $50 \% \leq \mathrm{FEV}_{1}<80 \%$ predicted, GOLD 3: $30 \% \leq$ $\mathrm{FEV}_{1}<50 \%$ predicted, GOLD $4: \mathrm{FEV}_{1}<30 \%$ predicted) [16]. Frequent exacerbations were defined as at least 2 exacerbations in the past 12 months [16, 17]. All subjects provided their written informed consent to the study (Research and Innovation in Chronic Inflammatory Respiratory Diseases-RINNOPARI, NCT02924818).
A

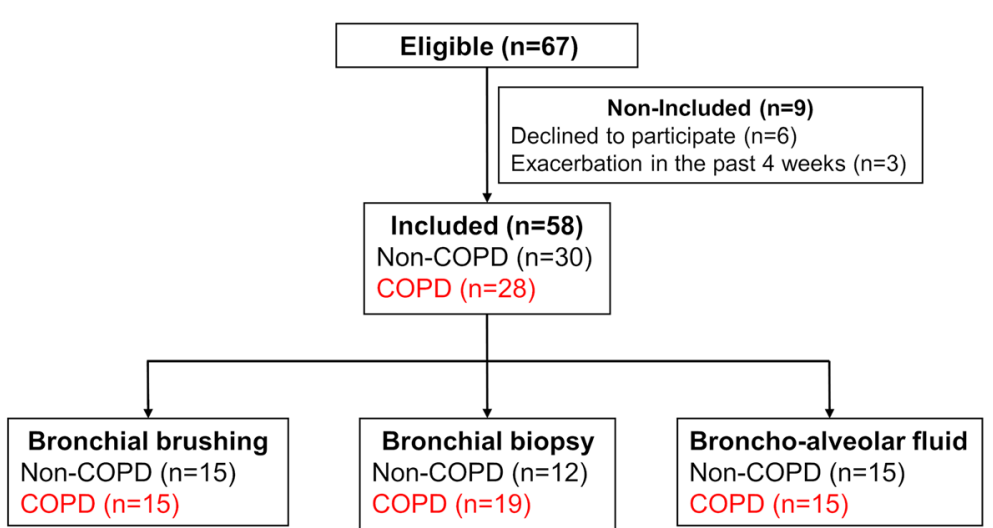

B

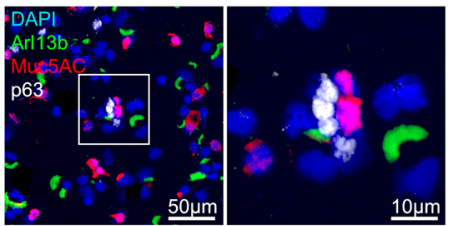

C

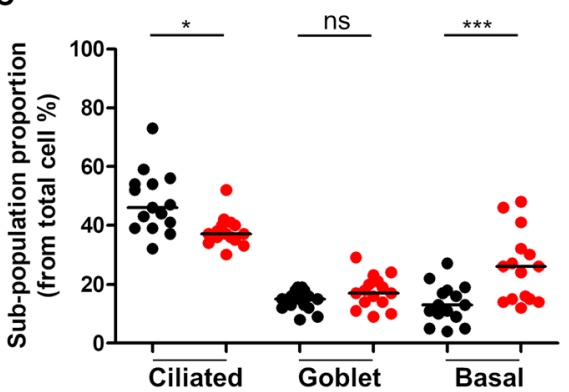

Fig. 1 Airway progenitor basal cell population is enriched in COPD. a. Study flow chart. b. Representative micrograph showing a Region of Interest (ROI) containing AEC obtained by bronchial brushing in a non-COPD patient stained for cilia (Arl13b, green); mucins (Muc5ac, red); basal cells (p63, white) and cell nuclei (DAPI, blue). Magnification corresponding to the selected area is shown. C. Dot plot with median showing the percentage of ciliated, goblet and basal cells in both non-COPD $(n=15)$ (black circle) and COPD patients $(n=15)$ (red circle). ${ }^{*}, p<0.05$ and ${ }^{* * *}$, $p<0.0001$; non-COPD vs COPD 
All subjects underwent fiberoptic bronchoscopy with bronchial brushings, biopsies and/or bronchoalveolar lavage (BAL) under routine clinical conditions according to international guidelines [18].

\section{Sample processing}

Fresh airway epithelial cells (AEC) obtained from bronchial brushings (right lower lobe) were suspended within 30 min in RPMI (1\% penicillin/streptomycin + 10\% BSA) before centrifugation $(12,500 \mathrm{rpm}$ twice). The cell pellet was dissociated in $1 \mathrm{~mL}$ of Trypsin-Versene ${ }^{\circ}$ and centrifuged (12,500 rpm twice). Cells were counted using a haemocytometer. Microscopy slides were coated with $100 \mu \mathrm{L}$ of $3 \%$ PBS-BSA by centrifugation $(10,000 \mathrm{rpm}$ for $10 \mathrm{~min}$ ) and 25,000 AEC were then centrifuged (750 rpm for $8 \mathrm{~min}$ ). Cells were immediately fixed with ice-cold methanol and stored at $4{ }^{\circ} \mathrm{C}$ until immunofluorescence analysis.

Bronchial biopsies (3rd to 5th order) were fixed in 4\% formalin for $24 \mathrm{~h}$. Three $\mu \mathrm{m}$ sections were cut from formalin-fixed paraffin-embedded (FFPE) blocks and processed for $H \& E$ staining and observed under the microscope $(\times 20)$ to confirm the presence of epithelium. Suitable FFPE bronchial section slides were deparaffinised before immunofluorescence staining.

BALF was sampled by fractionating aliquots of bronchial (first $50 \mathrm{~mL}$ ) and alveolar samples $(100 \mathrm{~mL})$ centrifuged twice at $1300 \mathrm{rpm}$ for $5 \mathrm{~min}$ [19]. Supernatants were collected and stored at $-80^{\circ} \mathrm{C}$ until ELISA analysis.

\section{Immunofluorescence staining}

Samples were rehydrated with PBS and blocked with $10 \%$ PBS-BSA for $30 \mathrm{~min}$ at room temperature before incubation with the following primary antibodies overnight at $4{ }^{\circ} \mathrm{C}$ in 3\% PBS-BSA: rabbit anti-Arl13b (17711-1-ap, ProteinTech, 1:200); mouse anti-Muc5ac (NBP2-15196, Novus Biologicals, 1:100); mouse anti-Acetylated- $\alpha$-tubulin (T6793, Sigma Aldrich, 1:1000); goat anti-p63 (AF1916, R\&D systems, 1:100); rabbit anti-pancytokeratin (E-AB33599; Clinisciences, 1:100); mouse anti-vimentin (M0725; Dako, 1:100); rabbit anti-Gli1 (HPA065172, Sigma Aldrich, $1 \mu \mathrm{g} / \mathrm{mL}$ ); rabbit anti-Gli2 (HPA074275, Sigma Aldrich, 0, $4 \mu \mathrm{g} / \mathrm{mL}$ ); goat anti-Shh (AF464, R\&D systems, 1:100); rabbit anti-Ptch1 (E-AB-10571, Clinisciences, 1:100); mouse anti-Hhip (WH0064399M1, Sigma-Aldrich, 1:100). Samples were washed with PBS and incubated with the appropriate secondary antibodies in PBS-BSA $3 \%$ for $1 \mathrm{~h}$ at room temperature. DNA was stained with DAPI (1:1000) during incubation with secondary antibodies. Negative controls were performed by omitting the primary antibody or by incubating with a corresponding IgG isotype.

Cells and bronchial sections were semi-automatically digitized into virtual slides using a VS120 virtual slide microscope at 20x magnification (NA 0.75) (Olympus,
Tokyo, Japan) and consulted with OlyVIA $^{\mathrm{mw}}$ viewer (Olympus). Cytological integrity and delimitation of individual cells were verified by light microscopy. Three regions of interest $(1000 * 1000$ pixels by ROI) were randomly extracted by BIOP VSI reader export plug-in (https://biop.epfl.ch/TOOL_VSI_Reader.html) and processed with ImageJ (National Institutes of Health) for analysis (450 cells were counted per slide).

\section{Shh enzyme-linked ImmunoSorbent assay}

Shh protein concentrations in BALF were assayed by enzyme-linked immunosorbent assay (ELISA) according to RayBiotech instructions (ELH-ShhN-001). The limit of detection of the assay was $8 \mathrm{pg} / \mathrm{mL}$.

\section{Validation cohort}

To validate our observations, we analysed human lung gene expression on an independent cohort (GSE47460) dataset including 145 COPD subjects and 91 control subjects $[20,21]$.

\section{Statistical analysis}

Data are expressed as mean \pm standard deviation (SEM). All continuous variables are represented with dot-plot and median. Associations between features were studied using Chi-square or Fisher's exact test, as appropriate. A non-parametric Mann-Whitney test was used to analyse differences between experimental conditions and linear regression was performed with the Spearman process. Multiple groups were analysed using the Kruskal-Wallis procedure followed by the Conover and Iman test. To evaluate differences in expression levels between candidate genes, we used the Mann-Whitney $U$ test for independent samples of the normalized log2-transformed microarray expression values. In all exploratory analyses, results with two-sided $p$-value $\leq 0.05$ were considered significant. XLSTAT software (Addinsoft Company, Paris, France) was used to analyse and format data.

\section{Results \\ Patient characteristics}

We included 30 non-COPD patients and 28 COPD patients to investigate $\mathrm{HH}$ pathway alterations in bronchial brushings, biopsies and BALF (Fig. 1a). The two groups did not differ in terms of age or sex (Table 1). As expected, COPD patients were more frequently current smokers and were characterized by higher smoking exposure, dyspnoea and airflow limitation. Twenty (71\%) COPD patients had at least one inhaled treatment. Nineteen $(68 \%)$ patients frequently used LABA, while 14 (50\%) and 13 (46\%) were treated with LAMA and ICS, respectively. 
Table 1 Baseline characteristics of the population

\begin{tabular}{|c|c|c|c|}
\hline & Non-COPD $(n=30)$ & $\operatorname{COPD}(n=28)$ & $p$-value \\
\hline Sex ratio $\mathrm{H} / \mathrm{F}$ & $13 / 17$ & $17 / 11$ & ns \\
\hline Age (years) & $53.9 \pm 15.3$ & $62.1 \pm 10.6$ & ns \\
\hline Smoking history & & & 0.009 \\
\hline Never smokers & $8(27 \%)$ & 0 & \\
\hline Current-smokers & $12(40 \%)$ & $12(43 \%)$ & \\
\hline Former-smokers & $10(33 \%)$ & $16(57 \%)$ & \\
\hline Pack-years & $21 \pm 21$ & $41 \pm 22$ & $<0.001$ \\
\hline \multicolumn{4}{|l|}{ Spirometry } \\
\hline $\mathrm{FEV}_{1}, \%$ of predicted value & $97 \pm 19$ & $55 \pm 25$ & $<0.0001$ \\
\hline FVC, $\%$ of predicted value & $100 \pm 18$ & $82 \pm 20$ & 0.003 \\
\hline $\mathrm{FEV}_{1} / \mathrm{FVC} \%$ & $81 \pm 9$ & $49 \pm 12$ & $<0.0001$ \\
\hline Spirometric GOLD 1/2/3/4 & NA & $7 / 6 / 9 / 6$ & - \\
\hline GOLD ABCD (mMRC) & NA & $8 / 6 / 6 / 8$ & - \\
\hline GOLD ABCD (CAT) & NA & $7 / 7 / 4 / 10$ & - \\
\hline Frequent exacerbation (> 1/year) & - & $10(36 \%)$ & - \\
\hline
\end{tabular}

Data are expressed as mean \pm SD or number (\%) FEV forced expiratory volume in $1 \mathrm{~s}, F V C$ forced vital capacity, mMRC modified medical research council, CAT COPD assessment test

ns: non-significate

\section{Percentages of ciliated and basal AEC populations are altered in COPD patients}

Epithelial cell populations collected by bronchial brushing were characterized by immunostaining for ciliated $($ Arl13b+), goblet (Muc5ac+) and basal (p63+) cell markers (Supplemental Table 1 and Fig. 1b). Compared to non-COPD subjects, COPD subjects had lower percentages of ciliated cells ( $37 \pm 5 \%$ vs $48 \pm 10 \% ; p=0.045$ ) and higher percentages of basal cells $(26 \pm 11 \%$ vs $13 \pm$ $6 \% ; p<0.0001$ ), while similar percentages of goblet cells were observed in the non-COPD and COPD groups $(15 \pm 3 \%$ vs $17 \pm 5 \% ; p=0.154)$ (Fig. $1 c$ ).

\section{Gli2 is reduced in nuclear basal cells progenitors from COPD patients}

The number of Gli2-positive cells nuclei in total AEC obtained by bronchial brushing was decreased in the COPD group compared to the non-COPD group: $39 \%$ vs $49 \%$ of total AEC; $p=0.017$ (Fig. 2a and b). Focusing solely on basal cells, the number of Gli2-positive cell nuclei in basal cells was also decreased in the COPD group compared to the non-COPD group: $44 \%$ vs $91 \%$ of basal cells (mean, $p<0.0001$; Fig. $3 \mathrm{a}$ and b). We identified two different patterns of Gli2 cellular localization in COPD subjects: either complete loss of the transcription factor

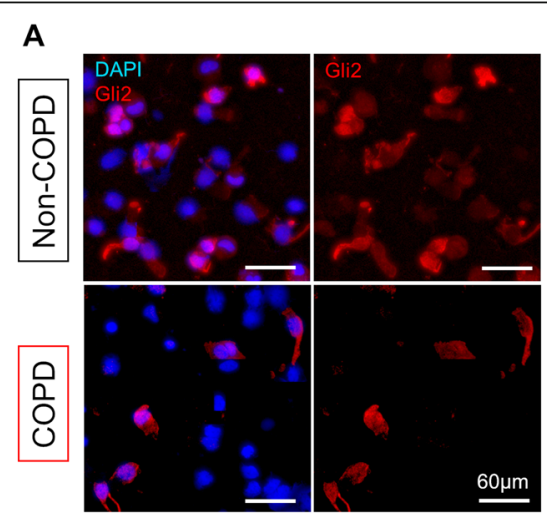

B

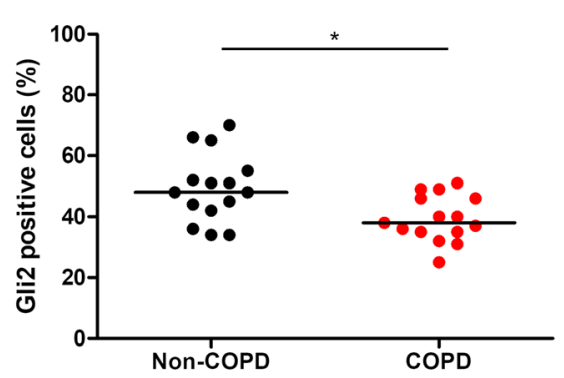

Fig. 2 Gli2 expression is decreased in AEC from COPD patients. a. Representative micrograph showing a ROI of a bronchial brushing stained for Gli2 (Gli2, red) and cell nuclei (DAPI, blue) in both non-COPD (upper panel) and COPD patients (lower panel). Magnification corresponding to the selected area is shown. $\mathbf{b}$. Dot plot with median showing the total percentage of Gli2-positive cells in non-COPD $(n=15)$ and COPD patients $(n=$ 15). ${ }^{*}, p<0.05$ 

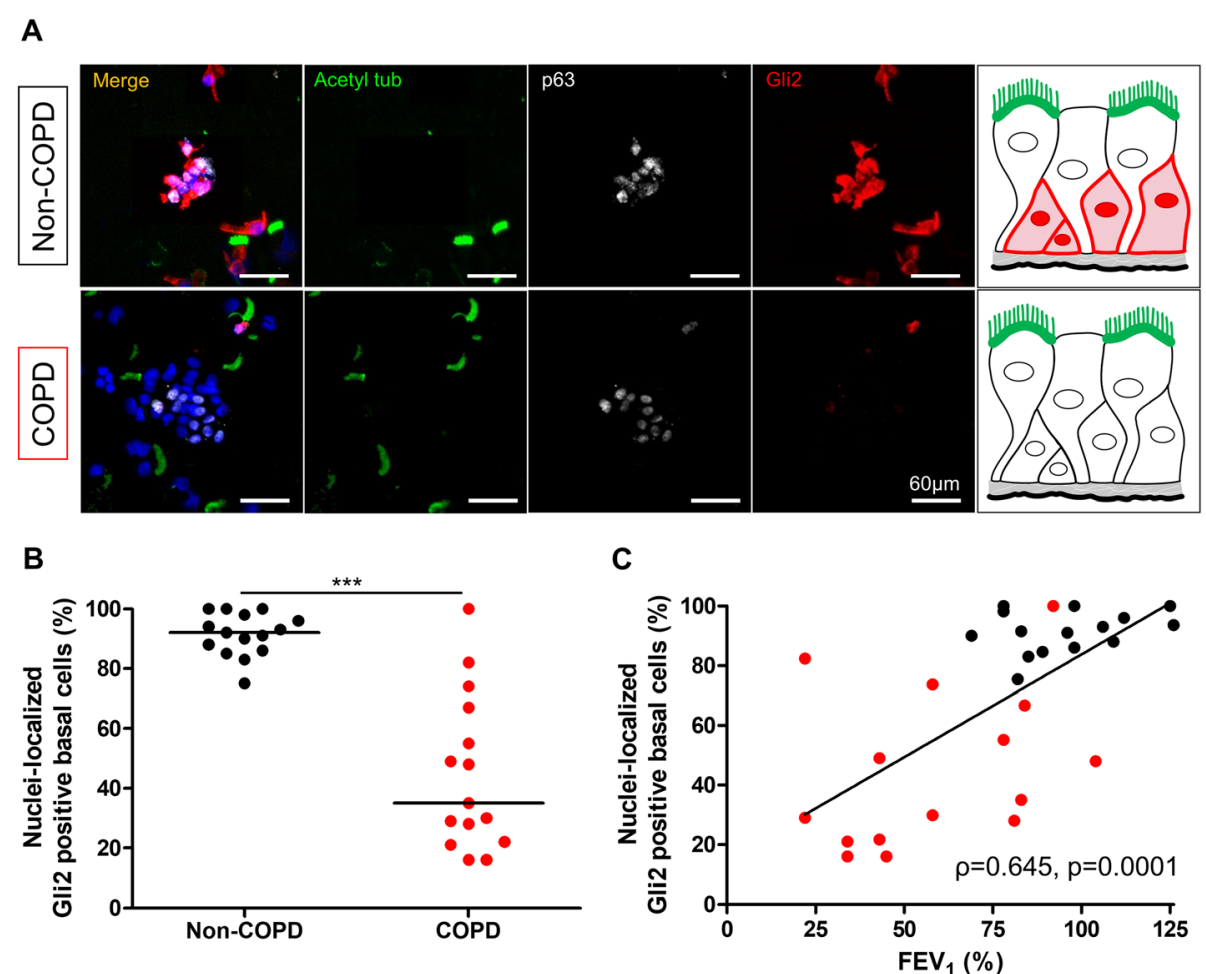

Fig. 3 Gli2 expression is decreased in airway progenitor basal cell nuclei from COPD patients. a. Representative micrograph showing a ROI of a bronchial brushing stained for cilia (Acetylated tubulin, green); Gli2 (Gli2, red); basal cells (p63, white) and cell nuclei (DAPI, blue) in both nonCOPD (upper panel) and COPD patients (lower panel). Magnification corresponding to the selected area is shown. Insets depict localization of the Gli2 transcription factor. $\mathbf{b}$. Dot plot with median showing the percentage of Gli2-positive basal cell nuclei in non-COPD $(n=15)$ and COPD patients $(n=15)$. ${ }^{* *}, p<0.0001$. c. Linear regression of the percentages of Gli2-positive basal cell nuclei according to FEV ${ }_{1}$ (\% predicted) for nonCOPD $(n=15)$ and COPD patients $(n=15)$. Non-COPD patients are represented by black circles and COPD patients are represented by red circles

or cytoplasmic-restricted localization (Supplemental Figure 1).

Lower Gli2 nuclear staining in basal cells was associated with lower $\operatorname{FEV}_{1}(\rho=0.645, p=0.0001$, Fig. 3c) and lower $\mathrm{FEV}_{1} / \mathrm{FVC}$ ratio $(\rho=0.737, p<0.0001$, Supplemental Figure 2A). No association was found between Gli2 nuclear staining and inhaled treatments, smoking history or clinical features (Supplemental Figure 2B).

\section{Alteration of Gli2 expression in bronchial epithelium and stroma from COPD patients}

We completed our approach by comparing $\mathrm{HH}$ components in bronchial biopsies. The material obtained by bronchial biopsies was situated more proximally than obtained by bronchial brushing, providing access to intact epithelia (Supplemental Table 2). The Gli2 distribution at this superior hierarchical airway branching was more diffuse, but a two-fold decrease of AEC Gli2 staining in bronchial epithelium was observed in the COPD group compared to the non-COPD group $(p=0.008$, Fig. 4a and b). As observed in AEC obtained by bronchial brushing, decreased Gli2 staining in bronchial epithelium was associated with lower $\operatorname{FEV}_{1}(\rho=0.413$, $p=0.022$; Fig. $4 \mathrm{c})$ and lower $\mathrm{FEV}_{1} / \mathrm{FVC}$ ratio $(\rho=0.411$, $p=0.022$; Supplemental Figure 3).

Since $\mathrm{HH}$ pathway homeostasis may rely on molecular crosstalks between stromal populations and AEC [10, 2224], we assessed $\mathrm{HH}$ mesenchymal response in peribronchial tissues (Supplemental Figure 4). Mesenchymal cells (stained for vimentin) were sparsely distributed in the stroma, and we observed differences in terms of activation between tissues from non-COPD and COPD patients. Few mesenchymal cells were Gli1+ in both groups, and we observed a gradient of Gli2+ cells in the stroma from the epithelial layer to the adventitia. Gli2+ mesenchymal cells were also decreased in the stroma of COPD patients.

\section{Reception of Shh signalling is altered in COPD patients}

To identify a potential mechanism involved in the Shh pathway dysregulation observed in COPD, we first investigated the localizations of the two main receptors of the ligand: Ptch1 and Hhip. In AEC (Fig. 5a), Ptch1 stained non-differentiated and differentiated cells, in which it was also found to be associated with Gli2 staining, suggesting that both cell populations may transduce Shh signalling. On the contrary, Hhip was not found on non- 

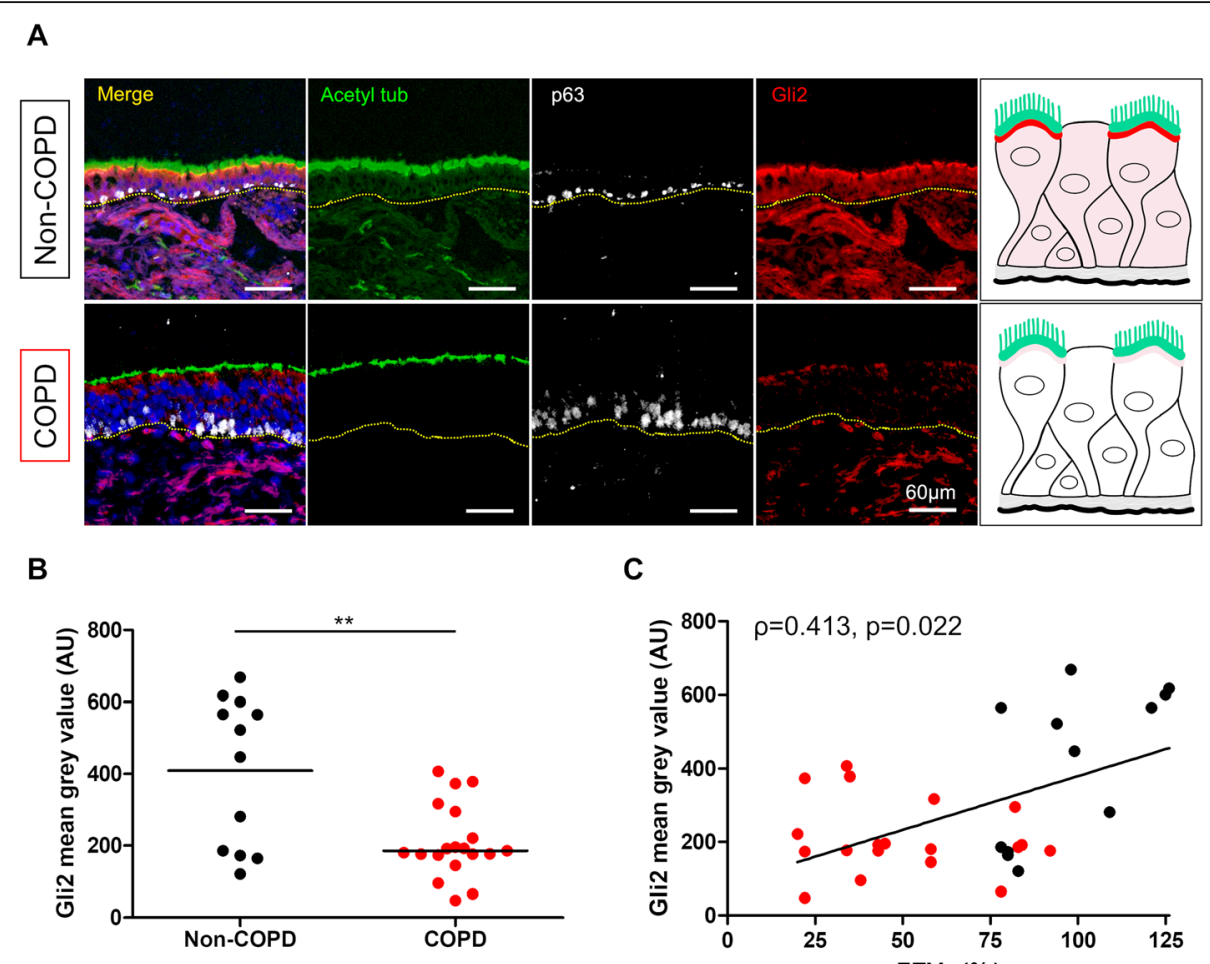

C

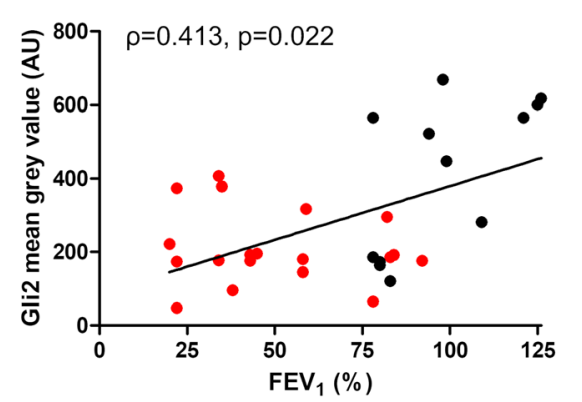

Fig. 4 Gli2 transcription factor is decreased in whole bronchial epithelium from COPD patients. a. Representative micrograph showing a ROI of a bronchial biopsy stained for cilia (Acetylated tubulin, green); Gli2 (Gli2, red); basal cells (p63, white) and cell nuclei (DAPI, blue) in both non-COPD (upper panel) and COPD patients (lower panel). Magnification corresponding to the selected area is shown. Insets depict localization of the Gli2 transcription factor. b. Dot plot with median showing the intensity of Gli2 mean grey value (Arbitrary units, AU) in whole bronchial epithelium in non-COPD $(n=12)$ and COPD patients $(n=19) . *^{*}, p<0.001$ C. Linear regression of the intensity of Gli2 mean grey value according to FEV ${ }_{1}(\%$ predicted) in non-COPD $(n=12)$ and COPD patients $(n=19)$. Non-COPD patients are represented by black circles and COPD patients are represented by red circles

differentiated cells. No difference in terms of these two Shh receptors was observed between non-COPD and COPD patients. Immunostaining of bronchial epithelium (Fig. 5b) confirmed the findings observed on isolated AEC, with epithelial cytoplasmic localization for Ptch1 and cilia-associated localization for Hhip. Interestingly, no difference in terms of epithelial localizations of Ptch1 and Hhip was observed between non-COPD and COPD patients, whereas mesenchymal populations appeared to express Hhip in non-COPD tissues.

Due to the loss of cytoarchitecture in bronchial brushing samples, we also characterized Shh localization in bronchial biopsies (Fig. 5c). Shh appeared to be predominantly present at the apical surface of ciliated cells in non-COPD tissues, but was absent in COPD epithelia. We then separately analysed bronchial fluid (corresponding to the fluid collected from the first $50 \mathrm{~mL}$ of saline injected during BAL) and alveolar fluid (corresponding to the fluid collected from the last $100 \mathrm{~mL}$ of saline injected during BAL) (Fig. 5d and Supplemental Figure 5A) from $15 \mathrm{COPD}$ and 15 non-COPD subjects (Supplemental Table 3) and quantified the SHH pathway- activating ligand Shh by ELISA. We observed a dramatic reduction of Shh protein concentration in bronchial samples from COPD patients compared to non-COPD subjects ( $12.5 \mathrm{vs} 40.9 \mathrm{pg} / \mathrm{mL} ; p=0.002$; Fig. $5 \mathrm{~d})$. Shh protein was not detectable in $67 \%(n=10)$ of samples from COPD patients and in $20 \%(n=3)$ of samples from non-COPD subjects.

Analysis of alveolar BALF samples did not reveal any differences in Shh protein concentrations between COPD and non-COPD groups (17.6 vs $28.5 \mathrm{pg} / \mathrm{mL}$, respectively, $p=0.228$; Supplemental Figure 5A). In addition, there was no significant difference in terms of Shh concentrations among COPD patients according to inhaled corticosteroid treatment (Supplemental Figure 5B).

\section{Shh ligand is deficient in COPD lung tissues}

To validate our results in an independent cohort, we then analysed a transcriptomic dataset obtained by RNA sequencing of lung tissue in COPD and non-COPD subjects (GSE47460). We confirmed a significant reduction in $\mathrm{SHH}$ gene expression in the COPD group compared to the non-COPD group (3.666 vs $3.883, \log 2$ relative 

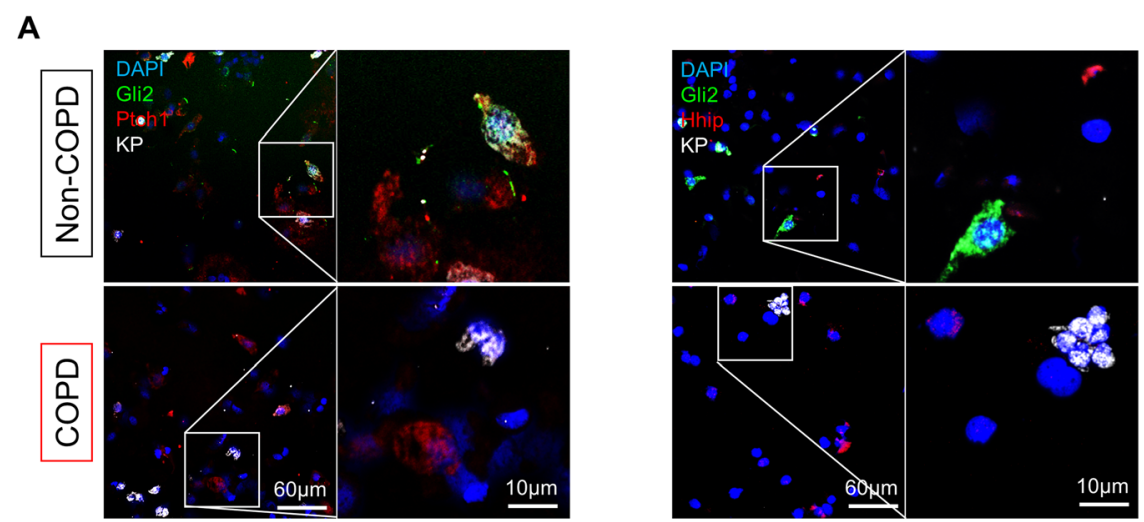

B
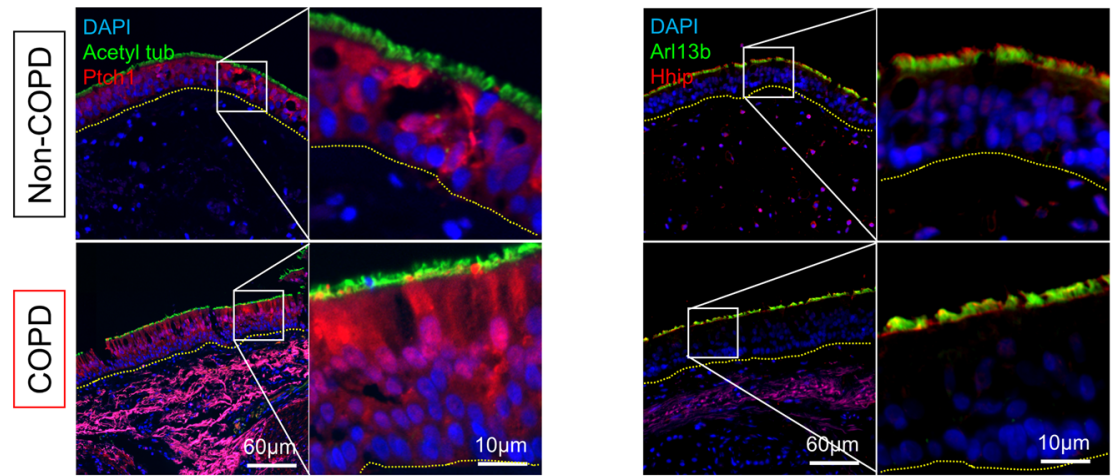

C

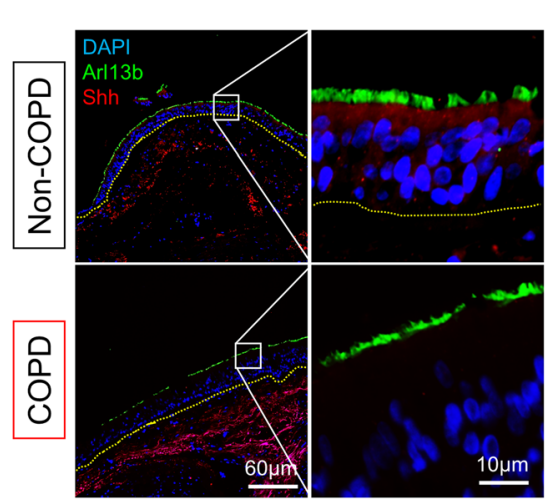

D

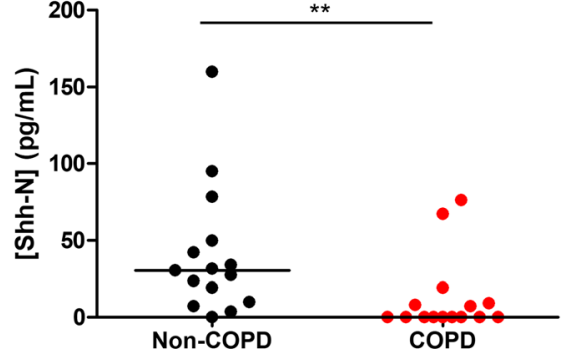

Fig. 5 Shh activating ligand is deficient in COPD bronchi. a. Representative micrograph showing a ROI of a bronchial brushing stained for basal cells (pancytokeratin, KP, white); Gli2 (green); Ptch1 (red, left panel); Hhip (red, right panel); and cell nuclei (DAPI, blue). Magnification corresponding to the selected area is shown. $\mathbf{b}$. Representative micrograph showing a ROI of a bronchial biopsy stained for cilia (Acetylated tubulin or Arl13b, green); Ptch1 (red, left panel); Hhip (red, right panel); and cell nuclei (DAPI, blue). Magnification corresponding to the selected area is shown. c. Representative micrograph showing a ROI of a bronchial biopsy stained for cilia (Arl13b, green); Shh (red) and cell nuclei (DAPI, blue). Magnification corresponding to the selected area is shown. $\mathbf{d}$. Dot plot with median representing Shh concentrations measured by ELISA in bronchial BALF from non-COPD $(n=15)$ and COPD patients $(n=15) .{ }^{* *}, p<0.001$

expression, $p=0.0001$; Fig. 6). SHH gene expression was not associated with smoking history, inhaled treatment or clinical features.

\section{Discussion}

In this prospective translational study, we demonstrated a marked dysregulation of the $\mathrm{HH}$ pathway in COPD patients by means of minimally invasive endobronchial procedures allowing the collection and analysis of several complementary biological samples. This approach provided access to cancer-free patients, thereby avoiding a major confounding bias in $\mathrm{HH}$ evaluation and allowed us to categorize patients with mild to very severe COPD, providing a representative range of severity. 


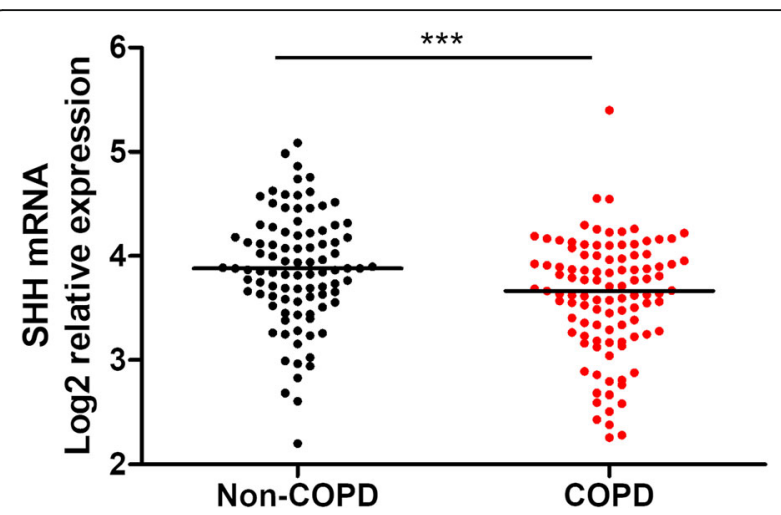

Fig. 6 Shh transcript levels are decreased in COPD lung tissues. Dot plot with median showing normalized expression of Log2transformed SHH expression in lung tissue from non-COPD $(n=91)$ and COPD patients $(n=145)$. ${ }^{* *}, p<0.0001$. Transcript expression microarrays were extracted from the GSE47460 dataset available at (https://www.ncbi.nlm.nih.gov/gds). Non-COPD patients are represented by black circles and COPD patients are represented by red circles

Using this approach, we confirmed alterations of AEC proportions in COPD, including an increase in basal cells and a dramatic reduction of the number of ciliated cells, as previously described [3], suggesting an impaired airway basal cell progenitor differentiation process [25]. Ideally, this basic quantification could be completed by cellular characterization using additional cell markers, possibly resulting in a single cell sequencing approach, such as the recent findings obtained in the fields of in vitro AEC differentiation, idiopathic pulmonary fibrosis or asthma [26-30]. Our recently published results suggested a role of the $\mathrm{HH}$ pathway in dysregulation of basal cell differentiation that could result in epithelial remodelling, a key feature of COPD [15].

To further explore this hypothesis, we then focused on the critical molecular players responsible for the biological effects of the $\mathrm{HH}$ pathway: the activating ligand, Shh, its main receptor Ptch1, its main co-receptor Hhip, and its main transcription factor Gli2, while previous studies have exclusively focused on analysis of the Ptch1 ligand receptor [31]. We first identified a marked decrease in Gli2 nuclear localization of basal cells and Gli2 protein levels in bronchial epithelium, highlighting a defect in $\mathrm{HH}$ signalling in COPD. The observed decrease of Gli2+ nuclear staining of cells obtained by bronchial brushing was consistent with our previous findings [15]. The apparent discrepancy with the staining observed on bronchial biopsies could be explained by the different sources of biological material. Moreover, accumulation of Gli2 on the apical cell surface may facilitate rapid activation of the $\mathrm{HH}$ pathway in these cells.

$\mathrm{HH}$ signalling partially orchestrates mesenchymal cell homeostasis during organogenesis and cellular crosstalks may be altered, as in idiopathic pulmonary fibrosis [10]. Our preliminary observations in stroma need to be confirmed by further investigations, as active proliferation in response to Shh signalling may occur exclusively during the process of connective tissue remodelling.

In concordance with our recent observations on FFPE tissues from lung resections [15], Ptch1, the receptor responsible for transduction of Shh signalling, was also found on non-differentiated and differentiated cells from isolated AEC and biopsies. Gli2 may be found in basal AEC nuclei, but can also be observed subciliary in ciliated cells, suggesting the presence of autocrine and paracrine signalling in the epithelium. We then focused on Hhip, another Shh receptor acting as an inhibitor of $\mathrm{HH}$ signalling, which is particularly interesting, as genetic alteration of Hhip was associated with COPD and emphysema in genome-wide associated studies and murine models $[4,5,31-35]$. We detected Hhip in differentiated cells, but the absence of differential Hhip localization between non-COPD and COPD samples suggested that genetic alterations of Hhip may impact protein function rather than protein expression.

We also analysed the $\mathrm{SHH}$ pathway-activating ligand Shh in bronchial biopsies and observed a loss of Shh on the apical surface of ciliated cells, which was confirmed in bronchial fluids, in which Shh ligand concentrations were decreased in COPD subjects. Altogether, our results suggest dysregulation of the $\mathrm{SHH}$ pathway either at the level of the production of the ligand or affecting the activating/inhibiting receptor binding balance in COPD.

This result was confirmed using the lung transcriptome dataset from of an independent COPD cohort. Although significant, the minor differences in gene expression levels observed may be due to the sample collection technique, involving extraction of mRNA from both epithelium and subepithelial compartments with enriched $\mathrm{HH}$ players, such as fibroblasts [36].

Our results are consistent with our previous observations showing that prevention of ligand-induced $\mathrm{HH}$ activation resulted in epithelial remodelling with an increased number of basal cells and decreased ciliogenesis [15], therefore mimicking the remodelling features of COPD observed in endobronchial samples in our study.

$\mathrm{HH}$ signalling has been associated with several respiratory diseases, including exacerbation of pulmonary fibrosis [10, 37], asthma [13, 38] or pulmonary arterial hypertension [39]. SHH signalling activation has also been associated with cigarette smoke [40, 41]. In our study, Shh pathway markers were not associated with smoking history or inhaled corticosteroid treatment. A previous high content screening study reported corticosteroid-mediated Shh modification [42]. Budesonide inhibited $\mathrm{HH}$ signalling, while other compounds 
failed to trigger pathway activation, increasing cellular sensitivity to $\mathrm{HH}$ ligands and impairing pathway inhibition by co-administered pharmacological antagonists of Smo signalling. The heterogeneity of inhaled corticosteroids and variable glucocorticoid concentrations in airways [43] could explain the absence of any corticosteroid-associated impact on $\mathrm{HH}$ activity in our study.

In this study, we confirmed that the $\mathrm{HH}$ pathway is clearly deficient in bronchial epithelium from COPD patients. Importantly, $\mathrm{HH}$ dysregulations were detected on a wide range of respiratory tract specimens: isolated AEC from bronchial brushing, bronchial biopsies, BAL and lung tissues. We also demonstrated, for the first time, that $\mathrm{HH}$ pathway inactivation is associated with the absence of its canonical activating ligand, Shh. Investigating the molecular mechanisms involved in Shhassociated epithelial remodelling may pave the way to characterization of novel markers in order to improve the management of COPD patients.

\section{Conclusions}

Our study, based on endobronchial samplings, confirmed dysregulation of Sonic $\mathrm{HH}$ signalling in COPD via the Gli2 transcription factor. More importantly, we demonstrated that $\mathrm{HH}$ impairment was related to Shh ligand deficiency in bronchial samples. These results highlight the major implication of $\mathrm{HH}$ in COPD. However, the relevance of these findings in terms of phenotyping and a potential innovative therapeutic target need to be further evaluated.

\section{Supplementary information}

Supplementary information accompanies this paper at https://doi.org/10. 1186/s12931-020-01478-X.

Additional file 1: Table S1. Baseline characteristics of the population who underwent bronchial brushing.

Additional file 2: Table S2. Baseline characteristics of the population who underwent bronchial biopsies.

Additional file 3: Table S3. Baseline characteristics of the population who underwent broncho-alveolar lavages.

Additional file 4: Figure S1. Heterogeneous Gli2 localization pattern in airway progenitor basal cells from COPD patients. Representative micrograph showing a Region Of Interest of a bronchial brushing stained for cilia (Acetylated tubulin, green); Gli2 (Gli2, red); basal cell (p63, white) and cell nuclei (DAPI, blue) both in COPD. Magnification corresponding to the selected area is shown. Insets depict localization of the Gli2 transcription factor.

Additional file 5: Figure S2. Nuclear localized Gli2 is associated with $\mathrm{FEV}_{1} / \mathrm{FVC}$ but not with ICS. A. Linear regression of the percentages of nuclear Gli2-positive basal cells according to $\mathrm{FEV}_{1} / \mathrm{FVC}$ (\% predicted) for non-COPD $(n=15)$ and COPD patients $(n=15)$. B. Dot plot with median, showing no association of the percentage of nuclear localized Gli2positive basal cells in COPD patients according to inhaled corticosteroid treatment (ICS). Non-COPD patients are represented by black circles and COPD patients are represented by red circles.

Additional file 6: Figure S3. Gli2 transcription factor in whole bronchial epithelium is associated to $\mathrm{FEV}_{1} / \mathrm{FVC}$ ratio. $\mathrm{A}$. Linear regression of the intensity of Gli2 mean grey value (Arbitrary Units, AU) in whole bronchial epithelium according to $\mathrm{FEV}_{1} / \mathrm{FVC}$ ratio (\% predicted) for nonCOPD $(n=12)$ and COPD patients $(n=19)$. Non-COPD patients are represented by black circles and COPD patients are represented by red circles.

Additional file 7: Figure S4. Peribronchial mesenchymal cells present no alteration of $\mathrm{HH}$ signalling in COPD patients. Representative micrograph showing a $\mathrm{ROI}$ of a bronchial biopsy stained for mesenchymal cells (vimentin, green); Gli1 (left, red) or Gli2 (right, red); and cell nuclei (DAPI, blue). Magnification corresponding to the selected area is shown.

Additional file 8: Figure S5. Shh activating ligand concentrations in alveolar BALF is not altered in COPD. A. Dot plot with median representing the Shh concentrations measured by ELISA in alveolar BALF from non-COPD $(n=15)$ and COPD patients $(n=15)$. B. Dot plot with median showing Shh concentrations in COPD patients according to inhaled corticosteroid treatment (ICS).

\section{Abbreviations}

COPD: Chronic obstructive pulmonary disease; HH: Hedgehog; $\mathrm{SHH}$ : Sonic hedgehog; AEC: Airway epithelial cell; RINNOPARI: Research and innovation in chronic inflammatory respiratory diseases; ROI: Region of interest; PFT: Pulmonary function tests; FEV $_{1}$ : Forced expiratory volume in 1-s; FVC: Forced vital capacity; GOLD: Global initiative for chronic obstructive lung disease; BSA: Bovine serum albumin; FFPE: Formalin-fixed paraffinembedded; ELISA: Enzyme-linked immunosorbent assay; CAT: COPD assessment test; mMRC: modified Medical Research Council; LABA: Longacting 32 -agonist; LAMA: Long-acting muscarinic antagonist; ICS: Inhaled corticosteroid; Gli2: Glioma-associated oncogene 2; Ptch1: Patched 1

\section{Acknowledgements}

We thank the members of the Inserm UMR-S 1250 unit and our colleagues for their helpful comments and insights. The authors thank A. Saul for assistance with English language editing. We thank the PICT platform (University of Reims Champagne-Ardenne) for technical assistance.

\section{Authors' contributions}

Concept and design: JA, GD, VD; Sample collection: JA, JMP, SD, PB, MD; Performed the experiments and data analysis: JA, RB, JMP, ZD, AB, NL, GD, VD; Preparation of manuscript and figures: JA, RB, JMP, MP, GD, VD. All authors have read and approved the final manuscript.

\section{Funding}

This work was supported by Funding from University of Reims ChampagneArdenne (URCA) and the French National Institute of Health and Medical Research (Inserm). It was carried out in the framework of the Federative Research Structure CAP-Santé.

\section{Availability of data and materials}

All data generated or analysed during this study are available from the corresponding author on reasonable request.

\section{Ethics approval and consent to participate}

Non-COPD and COPD patients were recruited from the Department of pulmonary medicine at University Hospital of Reims (France) and included in the Research and Innovation in Chronic Inflammatory Respiratory Diseases (RINNOPARI, NCT02924818) cohort. The study was approved by the ethics committee (CCP Dijon EST I, N²016-A00242-49) and was conducted in accordance with the ethical guidelines of the Declaration of Helsinki.

\section{Consent for publication}

All subjects gave their written informed consent prior to inclusion in the study.

\section{Competing interests}

Dr. Deslée reports personal fees from Nuvaira, personal fees from BTG/ PneumRx, personal fees from Chiesi, personal fees from Boehringer, personal fees from Astra Zeneca, outside the submitted work. Dr. Dury reports personal fees from Novartis, personal fees from Boehringer-Ingelheim, personal fees from Chiesi, personal fees from Roche, outside the submitted 
work. Dr. Dormoy reports personal fees from Chiesi outside the submitted work.

\section{Author details Reims, France. ${ }^{4}$ University Hospital of Reims, Hôpital Maison Blanche, Laboratoire de Biopathologie, 51092 Reims, France. \\ Received: 21 January 2020 Accepted: 2 August 2020 Published online: 07 August 2020}

'University of Reims Champagne-Ardenne, Inserm, P3Cell UMR-S 1250, SFR CAP-SANTE, 45 rue Cognacq-Jay, 51092 Reims, France. ${ }^{2}$ Department of Pulmonary Medicine, University Hospital of Reims, Hôpital Maison Blanche, 51092 Reims, France. ${ }^{3}$ Platform of Cellular and Tissular Imaging (PICT), 51097

\section{References}

1. Diaz-Guzman E, Mannino DM. Epidemiology and prevalence of chronic obstructive pulmonary disease. Clin Chest Med. 2014;35:7-16.

2. Jones RL, Noble PB, Elliot JG, James AL. Airway remodelling in COPD: It's not asthma! Respirol Carlton Vic. 2016;21:1347-56.

3. Ghosh M, Miller YE, Nakachi I, Kwon JB, Barón AE, Brantley AE, et al. Exhaustion of airway basal progenitor cells in early and established chronic obstructive pulmonary disease. Am J Respir Crit Care Med. 2018;197:885-96.

4. Siafakas N, Corlateanu A, Fouka E. Phenotyping before starting treatment in COPD? COPD. 2017;14:367-74.

5. Wain LV, Shrine N, Artigas MS, Erzurumluoglu AM, Noyvert B, Bossini-Castillo $L$, et al. Genome-wide association analyses for lung function and chronic obstructive pulmonary disease identify new loci and potential druggable targets. Nat Genet. 2017:49:416-25.

6. Obeidat M, Hao K, Bossé Y, Nickle DC, Nie Y, Postma DS, et al. Molecular mechanisms underlying variations in lung function: a systems genetics analysis. Lancet Respir Med. 2015;3:782-95.

7. Kugler MC, Joyner AL, Loomis CA, Munger JS. Sonic hedgehog signaling in the lung. From development to disease. Am J Respir Cell Mol Biol. 2015;52: $1-13$.

8. Wang $C$, Cassandras M, Peng T. The role of hedgehog signaling in adult lung regeneration and maintenance. J Dev Biol. 2019;7(3):14.

9. Carballo GB, Honorato JR, de Lopes GPF, Spohr TCLSE. A highlight on Sonic hedgehog pathway. Cell Commun Signal. 2018;16(1):11.

10. Cigna N, Farrokhi Moshai E, Brayer S, Marchal-Somme J, Wémeau-Stervinou L, Fabre $\mathrm{A}$, et al. The hedgehog system machinery controls transforming growth factor- $\beta$-dependent myofibroblastic differentiation in humans: involvement in idiopathic pulmonary fibrosis. Am J Pathol. 2012;181:2126-37.

11. Bolaños AL, Milla CM, Lira JC, Ramírez R, Checa M, Barrera L, et al. Role of sonic hedgehog in idiopathic pulmonary fibrosis. Am J Physiol Lung Cell Mol Physiol. 2012;303:L978-90.

12. Xu C, Zou C, Hussain M, Shi W, Shao Y, Jiang Z, et al. High expression of sonic hedgehog in allergic airway epithelia contributes to goblet cell metaplasia. Mucosal Immunol. 2018;11:1306-15.

13. Li X, Howard TD, Moore WC, Ampleford EJ, Li H, Busse WW, et al. Importance of hedgehog interacting protein and other lung function genes in asthma. J Allergy Clin Immunol. 2011;127:1457-65.

14. Giroux Leprieur E, Jablons DM, He B. Old sonic hedgehog, new tricks: a new paradigm in thoracic malignancies. Oncotarget. 2018:9:14680-91.

15. Belgacemi R, Luczka E, Ancel J, Diabasana Z, Perotin J-M, Germain A, et al. Airway epithelial cell differentiation relies on deficient hedgehog signalling in COPD. EBioMedicine. 2020;51:102572.

16. Vogelmeier CF, Criner GJ, Martinez FJ, Anzueto A, Barnes PJ, Bourbeau J, et al. Global strategy for the diagnosis, management, and prevention of chronic obstructive lung disease 2017 report. GOLD executive summary. Am J Respir Crit Care Med. 2017;195:557-82.

17. Hurst JR, Vestbo J, Anzueto A, Locantore N, Müllerova H, Tal-Singer R, et al. Susceptibility to exacerbation in chronic obstructive pulmonary disease. $\mathrm{N}$ Engl J Med. 2010;363:1128-38.

18. Du Rand IA, Blaikley J, Booton R, Chaudhuri N, Gupta V, Khalid S, et al. British Thoracic Society guideline for diagnostic flexible bronchoscopy in adults: accredited by NICE. Thorax. 2013;68(Suppl 1):i1-44.

19. Van Vyve T, Chanez P, Lacoste JY, Bousquet J, Michel FB, Godard P. Comparison between bronchial and alveolar samples of bronchoalveolar lavage fluid in asthma. Chest. 1992;102:356-61.
20. Cruz T, López-Giraldo A, Noell G, Casas-Recasens S, Garcia T, Molins L, et al. Multi-level immune response network in mild-moderate chronic obstructive pulmonary disease (COPD). Respir Res. 2019;20:152.

21. Scott M, Vallania F, Khatri P. Meta-analysis of continuous phenotypes identifies a gene signature that correlates with COPD disease status. Pac Symp Biocomput Pac Symp Biocomput. 2017;22:266-75.

22. Cao H, Chen X, Hou J, Wang C, Xiang Z, Shen Y, et al. The Shh/Gli signaling cascade regulates myofibroblastic activation of lung-resident mesenchymal stem cells via the modulation of Wnt10a expression during pulmonary fibrogenesis. Lab Investig. 2020;100:363-77.

23. Hu B, Liu J, Wu Z, Liu T, Ullenbruch MR, Ding L, et al. Reemergence of hedgehog mediates epithelial-Mesenchymal crosstalk in pulmonary fibrosis. Am J Respir Cell Mol Biol. 2015;52:418-28.

24. Hines EA, Sun $X$. Tissue crosstalk in lung development: tissue crosstalk in lung development. J Cell Biochem. 2014;115:1469-77.

25. Rock JR, Randell SH, Hogan BLM. Airway basal stem cells: a perspective on their roles in epithelial homeostasis and remodeling. Dis Model Mech. 2010; 3:545-56.

26. Vieira Braga FA, Kar G, Berg M, Carpaij OA, Polanski K, Simon LM, et al. A cellular census of human lungs identifies novel cell states in health and in asthma. Nat Med. 2019:25:1153-63.

27. Reyfman PA, Walter JM, Joshi N, Anekalla KR, McQuattie-Pimentel AC, Chiu $S$, et al. Single-cell Transcriptomic analysis of human lung provides insights into the pathobiology of pulmonary fibrosis. Am J Respir Crit Care Med. 2019;199:1517-36

28. Schiller HB, Montoro DT, Simon LM, Rawlins EL, Meyer KB, Strunz M, et al. The human lung cell atlas: a high-resolution reference map of the human lung in health and disease. Am J Respir Cell Mol Biol. 2019;61:31-41.

29. Zaragosi LE, Deprez M, Barbry P. Using single-cell RNA sequencing to unravel cell lineage relationships in the respiratory tract. Biochem Soc Trans. 2020;48:327-36.

30. Ruiz García S, Deprez M, Lebrigand K, Cavard A, Paquet A. Arguel M-J, et al. Dev Camb Engl: Novel dynamics of human mucociliary differentiation revealed by single-cell RNA sequencing of nasal epithelial cultures; 2019.

31. Tam A, Hughes M, McNagny KM, Obeidat M, Hackett TL, Leung JM, et al. Hedgehog signaling in the airway epithelium of patients with chronic obstructive pulmonary disease. Sci Rep. 2019;9:3353.

32. Bártholo TP, Porto LC, Pozzan R, Nascimento A, da Costa CH. Evaluation of HHIP polymorphisms and their relationship with chronic obstructive pulmonary disease phenotypes. Int J Chron Obstruct Pulmon Dis. 2019;14: 2267-72.

33. Yun JH, Morrow J, Owen CA, Qiu W, Glass K, Lao T, et al. Transcriptomic analysis of lung tissue from cigarette smoke-induced emphysema murine models and human chronic obstructive pulmonary disease show shared and distinct pathways. Am J Respir Cell Mol Biol. 2017;57:47-58.

34. Boueiz A, Lutz SM, Cho MH, Hersh CP, Bowler RP, Washko GR, et al. Genome-wide association study of the genetic determinants of emphysema distribution. Am J Respir Crit Care Med. 2017;195:757-71.

35. Lao T, Jiang Z, Yun J, Qiu W, Guo F, Huang C, et al. Hhip haploinsufficiency sensitizes mice to age-related emphysema. Proc Natl Acad Sci. 2016;113:E4681-7.

36. Zhu ZX, Sun CC, Ting Zhu Y, Wang Y, Wang T, Chi LS, et al. Hedgehog signaling contributes to basic fibroblast growth factor-regulated fibroblast migration. Exp Cell Res. 2017;355:83-94.

37. Moshai EF, Wémeau-Stervinou L, Cigna N, Brayer S, Sommé JM, Crestani B, et al. Targeting the hedgehog-glioma-associated oncogene homolog pathway inhibits bleomycin-induced lung fibrosis in mice. Am J Respir Cell Mol Biol. 2014;51:11-25.

38. Wang X-Z, Zhang H-H, Qian Y-L, Tang L-F. Sonic hedgehog (Shh) and CC chemokine ligand 2 signaling pathways in asthma. J Chin Med Assoc JCMA. 2019;82:343-50

39. Ghouleh IA, Sahoo S, Meijles DN, Amaral JH, de Jesus DS, Sembrat J, et al. Endothelial Nox1 oxidase assembly in human pulmonary arterial hypertension; driver of Gremlin1-mediated proliferation. Clin Sci Lond Engl 1979. 2017:131:2019-35.

40. Guo Y, Shi G, Wan H, Zhou M. Hedgehog signaling regulates the expression levels of inflammatory mediators in cigarette-induced airway inflammation. Mol Med Rep. 2018;17:8557-63.

41. Qin Y-X, Yang Z-H, Du X-H, Zhao H, Liu Y-B, Guo Z, et al. Inhibition of the Hedgehog Signaling Pathway Depresses the Cigarette Smoke-Induced Malignant Transformation of 16HBE Cells on a Microfluidic Chip. Chin Med J (Engl). 2018;131:1191-8. 
42. Wang Y, Davidow L, Arvanites AC, Blanchard J, Lam K, Xu K, et al. Glucocorticoid compounds modify smoothened localization and hedgehog pathway activity. Chem Biol. 2012;19:972-82.

43. Hübner M, Hochhaus G, Derendorf H. Comparative pharmacology, bioavailability, pharmacokinetics, and pharmacodynamics of inhaled glucocorticosteroids. Immunol Allergy Clin N Am. 2005;25:469-88.

\section{Publisher's Note}

Springer Nature remains neutral with regard to jurisdictional claims in published maps and institutional affiliations.

- fast, convenient online submission

- thorough peer review by experienced researchers in your field

- rapid publication on acceptance

- support for research data, including large and complex data types

- gold Open Access which fosters wider collaboration and increased citations

- maximum visibility for your research: over $100 \mathrm{M}$ website views per year

At $\mathrm{BMC}$, research is always in progress. 